is merely a vulgar fraction of a man and we put together without distinction the heads of the coalminer, the adolescent and the sedentary legislator.

A child's requirements for protein and calcium are proportionally higher than those of an adult. Its digestive machinery is less rugged and smaller and, since his body is growing, errors of diet in childhood may leave permanent effects. The child, then, has first call on milk. It is given supplies of vitamin $D$ in cod-liver oil and vitamin $\mathrm{C}$ in concentrated fruit juice. This simple application of nutritional knowledge has not been carried out without administrative and technical difficulty. A reduction of income tax is accepted as some recompense for the expense of a child, but the provision of low-priced or free milk and orange juice to meet the special needs of the child was a new step in enlightened public adminis. tration. To provide fruit juice as a source of vitamin $C$ it was necessary to enlist the help of analysts to insure that the stated concentration of vitamin was present in the preparation issued. This called for a certain change in outlook. The agricultural chemist is accustomed to analyse feed for its nutritive value. The analyst of human food, however, is usually engaged in a search for adulterants or preservatives.

Although the nutritive policy of the Ministry of Food is based on the distribution of equal shares to every individual, there is, in addition to the special individual provision of extra rations to children and expectant or nursing mothers and to certain invalids and other special categories, a group distribution to special classes. These classes are school children and industrial workers.

Hitherto it has been possible to obtain sufficient food to provide a nutritionally adequate diet for the population of Great Britain. First-class protein, fats and some other foods are rationed. By good fortune perhaps rather than by good management, of all nations in Europe only in Great Britain has it not yet been necessary to ration bread and potatoes. Nor are ration coupons demanded for communal meals. If bread, potatoes and communal meals were rationed in such a way as to make a material saving in food, it would probably be necessary to impose some measure of underfeeding.

To-day almost a quarter of the school-children in Great Britain receive their main meal of the day 'off the ration', and so do about an equal proportion of the industrial workers. The study of the nutritive value of these meals is an interesting matter. It has been investigated in a way similar in principle to the twofold scrutiny of the total national diet. First, the nutritive values of the catering allowances have been examined. An ordinary restaurant is allowed rations based on one pennyworth of meat per main meal. Industrial canteens receive a penny-halfpennyworth of meat and other additions. Canteens serving certain specified heavy industries are allowed two pennyworth of meat. School meals get the biggest allow. ances of all and two pennyworth of meat. The meat provided for the children is based on their high physiological needs of animal protein.

Rationed foods supply only a part of the total meal. Its full composition is based on custom, catering facilities and scientific advice. Those rem sponsible for communal catering are eager for nutritional advice which is difficult to give. Daily requirements of nutrients are known with some degree of precision, but little well-grounded information is available about the desirable value for a single meal. In order to find out the nutritional value of meals known to be satisfactory ; to be able to suggest improvements; and to investigate the effects on food values of large-scale catering, the Ministry of Food enlisted the voluntary co-operation of biochemists in more than a dozen towns. These publicspirited workers have analysed the meals and investigated nutritional problems which arise in providing them. This work is continuing.

A number of important technical advances have been made in fulfilling the Ministry's policy of providing a diet which people will eat and which will supply their physiological requirements. Of foremost importance is the national loaf. Eighty-five per cent of the wheat grain is used. The part which is discarded is the least digestible fraction. The discovery that a minute morphological structure, the scutellum, which divides the germ from the endosperm, is by far the richest in vitamin $B_{1}$ of all parts of the grain, has enabled a flour to be prepared which is high in vitamin content and low in fibre. A chronic deficiency of vitamin $B_{1}$ in the national diet widespread in peace-time has thus, been overcome. Other important advances have been the successful production of dried milk and dried egg. Dried meat, fish and vegetables are available for the Forces. The concentrated fruit juices as sources of vitamin $\mathrm{C}$ and perhaps other vitamins have already been mentioned.

The application of scientific planning to the nation's food calls for a better understanding by the public of the elementary principles of nutrition. The Ministry has in the past three years conducted an educational campaign stressing such points as the proper choice of foods for a balanced diet and the careful cooking of vegetables to preserve their vitamin.C. How far the effects of this campaign are permanent cannot be judged until the relaxation of war-time restrictions once again gives the housewife some freedom of choice. The success of the pre. dominantly scientific policy of the Ministry of Food can only be measured by the economies in shipping which it has rendered possible, and, most important of all, by the health of the nation. The national health has, so far, been well maintained. Clinical surveys for the assessment of nutritional well-being, which are carried out by the Ministry of Health and others, confirm what is suggested by the Ministry of Food's own surveys of food intake, that the rational distribution of the nation's food resources has caused, in general, an improvement rather than a deterioration in nutrition in Great Britain during these four years of war.

\section{BIOGEOCHEMICAL RESEARCH IN THE U.S.S.R.}

\section{By A. P. VINOGRADOV}

$\mathrm{G}$ EOLOGISTS have always taken an interest in the problem of the influence of life on the chemical processes going on within the earth's crust. In the early days of the Revolution, V. Vernadsky, first in the Ukrainian Academy of Sciences at Kiev and later in the Academy of Sciences of the U.S.S.R. in Leningrad, organized, on a very modest scale, experimental work in the study of the chemical composition of organisms. His friend and pupil, Prof. Y. Samoilov, of the University of Moscow, working independently, conducted research on the part played by organisms in the formation of soils. F. W. Clarke in his "Data of Geo-chemistry" 
(5th ed. 1924), the appearance of which opened up a new era, treats the same subjects mainly on the basis of American work.

It was, however, only after university courses delivered by Vernadsky in Prague, Paris and Leningrad, and the appearance of the fourth edition of his "Outline of Geochemistry" in 1930, that wide acceptance was given the postulate that the distribution, combination and migration of chemical elements in the earth's crust and in the biosphere could not be understood without taking into consideraation the influence of the sum total of all organisms.

Twenty years ago, when geochemical ideas were being crystallized and the young science was being formed, together with the laws of the distribution and combination of chemical elements, the migration of chemical elements, their dissemination and concentration, and the theory of the energy-levels of crystallized natural bodies, the lack of knowledge of the chemical composition of organisms and also of soils and organogenic rocks was very keenly felt.

In $1929 \mathrm{~V}$. I. Vernadsky founded the Biogeochemical Laboratory of the Academy of Sciences of the U.S.S.R. to study the laws of the distribution and migration of chemical elements in the biosphere, employing for the solution of these problems the whole arsenal of modern perfected analytical methodsspectroscopy, X-ray spectroscopy, mass spectroscopy and other chemical and physico-chemical methods. Similar research was begun later in the ChemicoRadiological Institute in Odessa, where the work was directed by Prof. E. Burkser, in the Geological Institute and the Institute of Soil Study of the Academy of Sciences of the U.S.S.R. and in other institutes. Research carried on in the Biogeochemical Laboratory and the researches of another Soviet geochemist, A. Fersman, published in his comprehensive work "Geochemistry" (1933-39) laid the foundation of geochemistry, of its zone of hypergenesis. In 1937 another of the founders of geochemistry, V. M. Goldschmidt, of Oslo, pointed out the significance of the work done by Vernadsky's school on the geochemistry of alluvial soils, and included them in his plan of experimental work.

Soviet men of science working in this field were mainly interested in the study of the laws of distribution between living matter, soil, surface waters and rare and disseminated chemical elements. On one hand, this research touched on the biochemistry of these elements, established as the result mainly of the work of G. Bertrand in Paris, and in the U.S.S.R. under the influence of the geochemical work of V. Vernadsky, in the Biochemical Institute of the Ukrainian Academy of Sciences, Prof. A. Pelladin, in the Pavlov Physiological Institute, by Prof. V. Sadikov and others; and on the other hand, it developed into the biochemistry of alluvial deposits. With regard to the former, stress must be laid on the present state of the question of the chemical composition of organisms in the light of geochemical conceptions.

During the past hundred years, the idea has developed that organisms consist of a limited number of certain chemical elements known as the biogenic elements. Completely new data on the systematic presence in organisms, in addition to others in soils and alluvial deposits, of bromine, iodine, fluorine, rubidium, lithium, nickel, cobalt, vanadium, titanium, molybdenum, lead, copper, strontium, barium, boron, radium and other strongly radioactive elements, the discovery of the rare elements germanium, gallium, niobium, selenium, chromium, zirconium and many others, found by and published in the papers from Vernadsky's school (A. Vinogradov, S. Borovik, V. Baranov, L. Selivanov, D. Maliuga, S. Sinyakova and others), enable us to put the question differently nowadays, and no longer to speak of which elements go to make up a living organism but rather of which elements have not yet been discovered in organisms; among these are indium, hafnium, niobium, tantalum, tungsten, radium and tellurium elements of the platinum group, although they have not yet been systematically sought. From a geochemical point of view, therefore, the organism and its environment are connected by the common history of all chemical elements. The question of the quantitative chemical composition of living matter and of various types of organism is therefore one of great interest. Here we will confine ourselves to the presentation of the geochemical curve of the distribution of chemical elements in organisms, which to some extent sums up our knowledge of this subject. The regularities observed in the average quantitative chemical composition stand out clearly when we compare the character of the curve with the character of analogous geochemical curves for soils and the earth's crust.

In general, the average chemical composition of organisms is reminiscent of the composition of soils forming the earth's crust. Chemical elements of low atomic number predominate. The position of certain chemical elements on that curve, lower or higher in comparison with the curve for soils and the earth's crust, may be explained by geochemistry. At the maxima of the curve we find those chemical elements which under biosphere conditions form easily moving compounds, gases, soluble salts, ete. ; while chemical elements at the minima of the curve do not form such compounds, as, for example, scandium, tin, titanium, hafnium, zirconium, thorium and many others. In spite of the frequently high content of the latter elements in soils and rocks, their content in organisms is one thousand to one ten-thousand times smaller. So far as the former are concerned, the concentrators are known; organisms in certain districts are greatly influenced by the insufficiency or abundance of these chemical elements in their environment.

That very brief and general outline of the geoehemical data of organisms with average chemical composition, the collection of which required a tremendous amount of labour and knowledge, must now serve as the basis for a theory of the comparative elemental composition of various species and the evolution of their chemical composition. These data show that the chemical composition of organisms is one of the distinguishing features of species.

The attention of Soviet investigators has been directed towards endemic diseases of plant life, animal life and man. Thanks to the expeditions of the People's Commissariat of Health of the U.S.S.R., the Biogeochemical Laboratory of the Academy of Sciences has at its disposal a considerable amount of material concerning the distribution of iodine in organisms, waters and soils from places with endemic goitre (the following were investigated: KabardinoBalkaria, Azerbaijan S.S.R., Mari A.S.S.R., Karelian A.S.S.R., Eastern Siberia and other districts of the Soviet Union). The data on iodine served as a basis for the systematic iodine treatment of the population which was carried out by the People's Commissariat of Health. These data enabled us to investigate the 
causes of an insufficiency of iodine in these districts. Similar geochemical research was carried out by the Biogeochemical Laboratory in the Urov region in eastern Siberia, which shows an insufficiency of calcium; soils of the Belorussian S.S.R. were investigated for copper content, insufficiency of which leads to a stunting of grain crops; investigation of soils of the U.S.S.R. in connexion with an insufficiency of boron leading to plant diseases, and a study of the flora in regions with excessive selenium content in the soil, etc. Investigations of this nature have enabled us to establish that at least twenty or thirty similar endemic diseases are connected with insufficiency or superfluity of certain chemical elements in the environment and have laid a scientific foundation for measures to be taken (A. Vinogradov).

Flora and fauna passing through such biogeochemical provinces are subjected to the specific influence of this insufficiency or superfluity of certain chemical elements. Some species acquire, as might have been expected, a certain physiological tolerance, as for example, tolerance to superfluous quantities of copper, nickel, lithium, etc., and form, apparently, races with a high content of these elements, whereas others die out. The question which has now arisen is whether certain species, concentrators of various chemical elements (for example, plants with high lithium content described by Vernadsky's school, plants rich in boron, plants concentrating molybdenum, etc.), came originally from similar biogeochemical provinces, and whether they show by their chemical composition signs of their origin.

As we have already said, the other side of the work of Soviet biogeochemists concerns problems connected with the geochemistry of alluvial deposits and rocks. It is, therefore, natural that sea deposits and the present geochemical processes going on in the depths of the sea should attract them. These researches have been developed side by side with oceanographical work in our seas, work which has been carried on at the State Oceanographical Institute.

A. Arkhangelsky has carried out extensive research on the presence of, and changes in, organic matter in Black Sea alluvial muds in connexion with the formation of oil deposits, the Oceanographic Institute has worked on the problem of obtaining a clear picture of the distribution of organic matter in the Barents and other Soviet seas; finally, a balance has been drawn up of organic matter, nitrogen and phosphorus in the Caspian Sea (S. Bruyevich). These and other similar investigations are all component parts of one and the same old, but nevertheless perpetually new, practical and very important problem of the fate of organic matter in the sea.

Sea organisms take part in a number of excep. tionally many-sided geochemical processes, as was shown in A. Vinogradov's paper "The Chemical Elemental Composition of the Sea". Here I can only mention a few new and more important facts and conclusions in this respyct. It has been proved that the concentration of iodine by seaweeds and still more by plankton diatoms creates the necessary condition for an accumulation of iodine in sea muds. During the process of the metamorphosis of muds, the iodine enters into solution with the water, forming strata of minera! iodine-bromide waters, which have considerable regional distribution and are a source of commercial iodine.

It has been further shown, for example, that exceptional concentrations of vanadium are deposited on the sea bed by Ascidians and are accumu- lated in the sea muds when the organisms perish. Radium and many other widely disseminated chemical elements are extracted from sea water by organisms. Research into the influence of organisms on the natural radioactive balance has shown in particular that various radioactive elements in the environment may be transformed into equivalent radioactive quantities (with equal number of disintegrating atoms), the absolute concentration of radioactive elements being changed a million times (V. Baranov).

The study of the migratory routes in the sea of boron, lithium and rubidium, which in general repeat the history of potassium, the picture of their dissemination given in the works of L. O. Solivanov, shows that although these elements are concentrated by organisms, in the final analysis they saturate and are accumulated in alluvial soils through water solutions in the form of chemical deposits. This is also to a considerable degree true of the formation of deposits of strontium and thorium salts occurring, for example, in the form of facies with celestite and rathite in the depths of the Permian Sea.

The formation of phosphate facies (and the formation of phosphorites) has been explained by A. Kazakov, also on the basis of research into the equilibrium of dilute solutions containing calcium and phosphate, as the appearance in water at certain depths in the zone of regeneration of organic phosphorus, deposits of calcium phosphate and apatite.

A few words about organogenic rocks. Thanks to the systematic study of the ashes of oils and solid bitumens, we have been able to discover the existence of oil-bearing regions where all the bitumens contain vanadium. The oils and hard bitumens of Baku, Grozny and other Caucasian oil-fields are practically free from vanadium. Nor, apparently, do the bitumens of Emba concentrate vanadium. The oils and asphalts of the Volga-Ural provinces, on the other hand, are extremely rich in vanadium, their vanadium content in some cases, for example in the ashes of Sadkin asphalt, being as much as 75 per cent $\mathrm{V}_{2} \mathrm{O}_{5}$. Priperchorsky district has oils with similar vanadium content.

On the basis of these geochemical data we may formulate the hypothesis that vanadium was selected from alluvial deposits in the sea by the primary matter of oil. The presence of vanadium, on account of its marked catalytic character, determines the later character of the oil, which as a rule has an asphalt base with a high sulphur content (A. Vinogradov).

At the same time, coal has been found with a large gerrnanium content. All this has given us reasons for investigating the processes of the accumulation of rare elements in coal with the object of searching for inclustrially useful concentrations (Biogeochemical Laboratory : S. Borovik, V. Ratynsky and others).

As a result of the accumulation of considerable data on the distribution of rare and widespread chemical elements in soils and strata, and the geochemical explanation of the history of these chemical elements, a method of correlation or indication of separate geological provinces in accordance with the distribution of microelements in them has been established. This opens up extensive prospects in the problem of drawing up a geochemical map of ancient processes in the earth's crust. Publications which have appeared during recent years on researches into the geochemistry of isotopes of the light elements have the same object (V. Vernadsky, P. Teis, A. Brodsky). 